\title{
TEST BENCH SOLAR POWER MEASUREMENT
}

This paper was downloaded from TechRxiv (https://www.techrxiv.org).

\section{LICENSE}

CC BY 4.0

SUBMISSION DATE / POSTED DATE

22-07-2021 / 26-07-2021

CITATION

Swarupa, Lakshmi (2021): TEST BENCH SOLAR POWER MEASUREMENT. TechRxiv. Preprint. https://doi.org/10.36227/techrxiv.15034758.v1

$\mathrm{DOI}$

10.36227/techrxiv.15034758.v1 


\title{
TEST BENCH SOLAR POWER MEASUREMENT
}

\author{
Mr.Banothu Suresh ${ }^{(\mathbf{1})}$ and Dr.M.Lakshmi Swarupa ${ }^{(2)}$ \\ ${ }^{1} \mathrm{PG}$ Scholar, CVR College of Engineering/EEE, Hyderabad, India \\ Email: sureshbanoth523@gmail.com \\ ${ }^{2}$ Professor, CVR College of Engineering/EEE, Hyderabad, India \\ Email: swarupamalladi@gmail.com
}

\begin{abstract}
Nowadays, Solar power is utilized more in domestic, commercial, and industrial applications. Solar energy is renewable energy which is produced from sun heat. In 2020 India solar installed capacity was $34,627 \mathrm{MW}$. In this paper developed an experimental setup for solar panel power measurement. In this current, voltage and light intensity has been measured. Declination angle of sun to earth is $+23.5^{\circ}$ degrees, $-\mathbf{2 3 . 5}^{\circ}$ degrees. The model of sun is represented by an incandescent bulb light and the angles set up manually. In this explained about solar power output at load side and see the variation between power and load resistance. Solar panel is generated power by light intensity applied by using incandescent light bulb. The light intensity changed by using a voltage regulator. The power is measured by using voltmeter and ammeter readings. Solar energy is to emulate the solar panel output power characteristics. The model of sun was taken as an incandescent bulb light and placed on the circular iron track to change east to the west. By changing the position of the bulb and changing the bulb light intensity with the help of the D.C speed regulator. Solar panel is placed in such a way that it freely moves to certain angles. By taking voltmeter and ammeter readings calculate the power. The graph is drawn between resistance versus power, the unique source of energy. The main aim of the paper is. Ensure that the maximum power output occurs at load which is taken as a resistor bank.
\end{abstract}

Keywords-Solar panel, light intensity, Resistor, voltage, current, power, incandescent bulb light

\section{INTRODUCTION}

Solar power is an alternative source which is available from the sun. Electrical power is generated from solar panel output D.C terminals. Solar energy is renewable energy. Most of the power systems generate power from resources such as coal, water etc.

Solar energy produced from sun rays is an inexhaustible source of convenient energy. Solar energy is electromagnetic energy. The sun rays falling on the earth's surface create angles. The photovoltaic effect principle is used to produce electricity. Solar energy depends on the sun. There is a need for monitoring and measurement of solar energy. The sun has produced energy for many years.

- The sun has produced energy for so many years. Solar energy is the sun's rays that reach to the earth surface.

- Solar energy is unique source of energy, and it can be exploited into useful form by different ways such as:

1. By direct conversion into fuel by photosynthesis.

2. By direct conversion into electricity by photovoltaic (PV).
3. By direct conversion into electricity through thermal electric power systems. In this system, the solar radiation is converted into heat energy which is further converted into mechanical energy and then into electrical energy.

- Solar power generation is increasing day by day. Solar energy is renewable which is produced from sunlight.

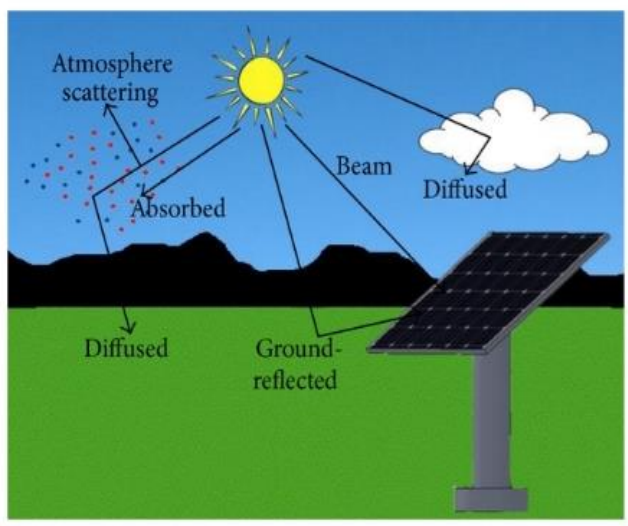

Fig 1: Sun rays falls on the earth surface.

- Atmospheric scattering is a natural phenomenon that can be described as the result of the interaction between sunlight and particles in the atmosphere.

- Diffuse radiation is solar radiation reaching the earth's surface after having been scattered from the direct solar beam by molecules in the atmosphere.

- Beam radiation is the solar radiation received from sun without having been scattered, whose direction same as the relative geometric position between the sun and earth.

Solar radiation near to the earth surface can be measured by following instruments Pyrheliometer, Radiometer, photo meter, Ground radio meter, Microwave radio meter, Multifilter rotating shadow band radiometer, Narrow field of view zenith radiometer etc.

\section{SOLAR POWER}

Solar energy is very important source of energy available to the earth and its inhabitants. Without sun there is no life on earth. Solar energy is responsible for all the biomass on the surface of the earth and its origin of fossil fuels. Solar energy creates the winds, evaporates the water which is responsible for rains, waves and ocean thermal power. 


\section{SOLAR ENERGY:}

Energy is the ability of an object to do some amount of work. Energy available in some forms like kinetic energy, potential energy.

Solar means the sun. solar energy is the energy of the sun. Every day the earth receives the energy directly from the sun. using some scientific methods solar energy can be converted in some useful form of energy. For example, we can convert solar energy into electrical energy and then converted in other form like heat energy, kinetic energy, potential energy etc. Solar energy reaches the earth in the form of waves which in sun light.one meter square area of the atmosphere $1.4 \mathrm{KW} / \mathrm{m}^{2}$ solar energy is produced and it is called as solar constant. Its outer side. The solar energy reduced because of gas particles, water vapors dust particles and reflection in atmosphere. The intensity of solar energy reaching the earth is around 1 $\mathrm{KW} / \mathrm{m}^{2}$.hence this energy used to heat water and produce the electricity. Solar energy is converted in to electrical energy by using photovoltaic cell which is made by using silicon.

\section{SOLAR CONSTANT:}

The is a large sphere of very hot gases, the heat being generated by various kinds of fusion reaction. Its diameter is $1.39 \times 10^{6} \mathrm{~km}$ while that of the earth is $1.27 \times 10^{4} \mathrm{~km}$. The mean distance between two is $1.5 \times 10^{8} \mathrm{~km}$ although the sun is large, it subtends an angle of only 32 minutes at the earth's surface. This is because it is also at a very large distance. Thus, the beam radiation received from the sun on the earth is almost parallel. The brightness of the sun varies from the center to its edge. However, for engineering calculations, it is customary to assume that the brightness all over the solar disc is uniform. As viewed from the earth, the radiation coming from the sun appears to be essentially equivalent to that coming from a black surface at 5262 degrees $\mathrm{K}$.

\section{PRINCIPLE OF CONVERSION OF SOLAR RADIATION INTO HEAT}

The fundamental process now in general used for heat conversion is the greenhouse effect. It is possible to grow exotic plants in cold climates through better utilization of the available sun light.

The best way to turn the energy contained in sun light into heat is solar thermal generation.it involves the sun as a source of heat in diffused from it arrives the earth. This heat is captured, concentrated with the help of solar collectors.

\section{COMPONENTS USED IN SOLAR POWER MEASUREMENT:}

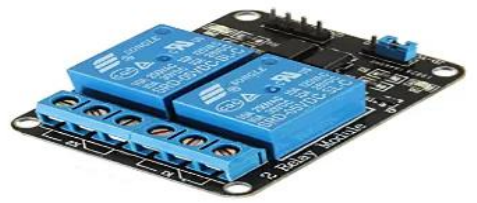

Fig 2: Two channel relay

Two channel transfer module is the module configuration to control two transfers in a basic manner and adaptable. It is being viable with Arduino, the hand-off module associated with the assistance of jumpers. By utilizing transfer mounted on module two Arduino computerized input/yield pins, it is feasible to control motors, inductive burdens, and other devices. This two-channel hand-off module is utilized in homegrown tasks and in broader in the space of mechanical technology papers. The module is outfitted with optocouplers on IN1 and IN2 lines so that it ensures the galvanic protection between the transfer load and the control board which drives this module. Associations Pin Capacity IN1 TTL advanced information IN2 TTL computerized input GND Ground $+5 \mathrm{~V}$ Force $(+5 \mathrm{~V})$ NO1 Regularly open contact COM1 Normal contact NC1 Typically shut contact 1 NO2 Ordinarily open contact COM2 Normal contact NC2 Ordinarily shut contact 2, Pin Capacity Supply voltage $+5 \mathrm{~V}$.

\section{INCANDESCENT BULB LIGHT}

Energy conservation is changing into additional of a priority. One resolution is to use additional energy economical bulbs reception, schools, businesses, and public places. This document can introduce key terms to use once talking concerning light weighting additionally as forms of light bulbs in use.

- Watt (abbreviated W) is that the unit adore the speed of energy consumption (or power) in an electrical circuit required during this case to lightweight a lightweight bulb.

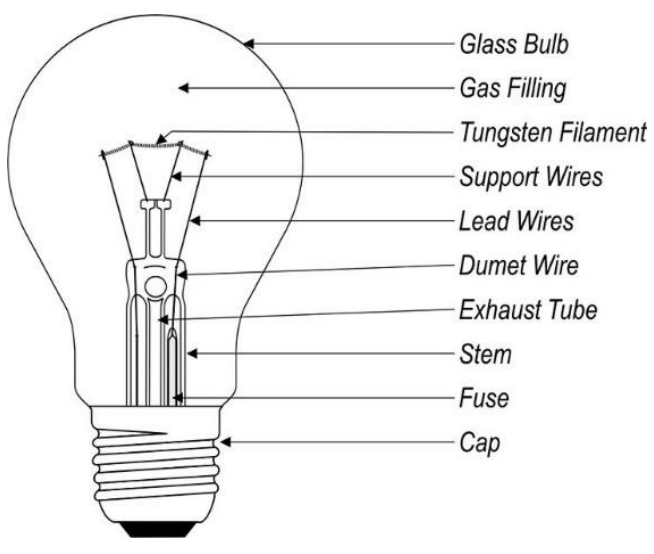

Fig 3: Incandescent bulb light

The incandescent lightweight bulb has had identical style for over a hundred years since Edison fictional it.

\section{ARDUINO MEGA}

Arduino mega microcontroller is associate degree open supply, computer onerous product and programming organization, activities, and shopper native space that plans and fabricates single board microcontroller units for building advanced gadgets and intuitive articles that may notice and management objects within the actual world. The comes things sent as ASCII text file instrumentality and programming, which area unit approved below the wildebeest lesser overall population license (LGPL) or the wildebeest overall population license (GPL), permitting the grouping of Arduino sheets and programming dissemination by anybody. Arduino sheets area unit accessible industrially in preassembled structure. 
Arduino board plans utilize associate degree assortment of microchips and controllers. The sheets area unit outfitted with sets of advanced and easy information/output(I/O) sticks that may be interfaced to completely different extension boards(shields)and different circuits. The sheets highlight successive interchanges interfaces, including Universal Serial Bus (USB) on sure models that area unit to boot used for stacking programs from PCs. The microcontrollers area unit unremarkably changed utilizing a jargon of highlights from the programming dialects $\mathrm{C}$ and $\mathrm{C}++$.In addition to utilizing typical compiler tool chains, the Arduino comes offers associate degree incorporated advancement environment (IDE) in sight of the handling language paper.

The Arduino comes began in 2003 as a program for understudies at association configuration foundation in Ivrea, Italy, aiming to provide lowest expense and easy ways that for fledglings and specialists to determine gadgets that interface with their current circumstance utilizing sensors and actuators. traditional instances of such gadgets papered for amateur specialist incorporate basic robots, indoor regulators and movement identifiers.

The name Arduino comes from bar in Ivrea, Italy, wherever some of the originators of the undertakings accustomed meet. The bar was named when Arduino of Ivrea, WHO was the margrave of the walk of Ivrea and lord of European country from 1002 to 1014.

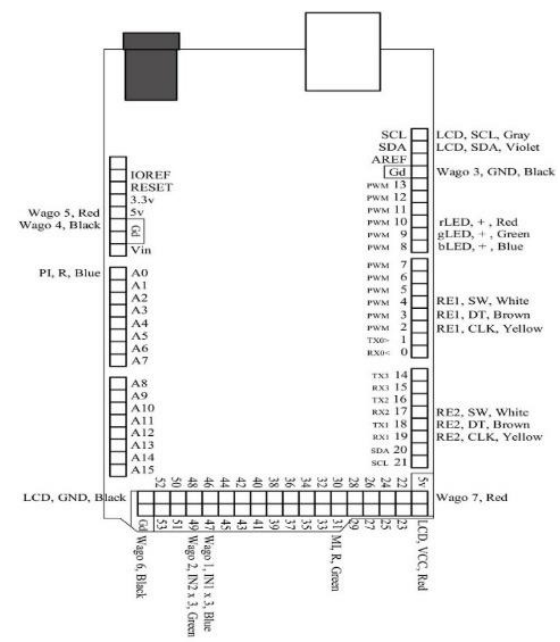

Fig 4: Arduino mega 2560 pin configuration

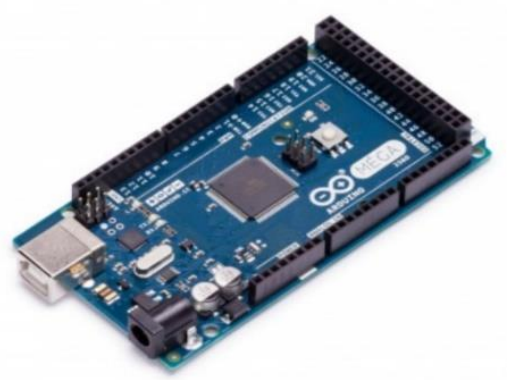

Fig 5: Arduino Mega 2560 layout

Arduino is basically a microcontroller which is control the relay functions. Arduino MEGA is used in this paper.

\section{POWER}

The Arduino Mega are often takes power through the USB association or with an outdoor power offer. The power offer is chosen mechanically. External(non-USB) force will return either from associate degree AC-to-DC adapter(wall-mole) or battery. The connecter is often associated by connecting a pair of $1 \mathrm{~mm}$ focus positive fitting to the board's force jack. Leads from A battery are often embedded within the Gnd and Vin pin headers of the force connecter. The board will work on associate degree outer stock of six to twenty volts. Whenever supplied with below $7 \mathrm{~V}$, however, the $5 \mathrm{~V}$ pin may provide below 5 volts and therefore the board can be insecure. within the event that utilizing a lot of than $12 \mathrm{~V}$, the voltage controller can be overheat and hurt the board. there is vary is seven to1 2 volts. The Mega 2560 not constant as each single going before board.

The power pins are as per the following:

- VIN: the data voltage to the Arduino board once it's utilizing associate degree outer force offer (rather than five volts from the USB association or different directed force source). you'll be able to offer voltage through this pin, or providing voltage by means that of the force jack, access it by means that of this pin.

- 5V: The managed power offers accustomed management the microcontroller and completely different segments on the board. this could return either from VIN by means that of associate degree on board regulator or provided purchase USB or another directed 5 Vsupply.

- 3V3: A 3.3 potential unit offer created by the on-board controller. Greatest current draw is $50 \mathrm{~mA}$.

\section{- GND: Ground pins.}

It is a type of microcontroller which is in smaller.it has $5 \mathrm{v}$, GND, A USB is connected for $5 \mathrm{~V}$ from CPU. It consists of 54 digital input/output pins, where 14 are PWM pins, 16 pins are Analog inputs, 6 hardware serial ports. It's controlled the wheels forward and backward movements by using switches. It's also used for irradiation measurement using sensor LDR and used for the relay operation.

\section{Electrical device (Transformer)}

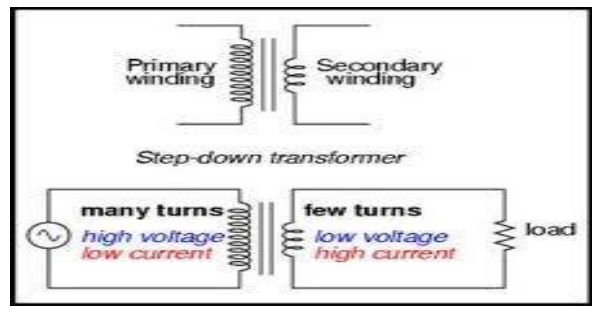

Fig 6: Transformer

- Transformer is a constant frequency device.

- Transformer is a constant power device.

- Transformer is an electromagnetic energy conversion device (Internal process).

- Complete transformer is not energy conversion device.

- It is a coupled circuit.

- Transformer is a constant flux device. 
- More number turns on the transformer side called as high voltage winding and lesser number of turns on the transformer side called low voltage winding.

- Supply connected to transformer called primary, load connected to transformer so called secondary.

- A step-down transformer is use for converting high voltage to low voltage. Generally, 230 volts, $50 \mathrm{HZ}$ A.C transformer is used.

\section{PUSH BUTTONS}

Press button is a switch which associates its terminal if it squeezed. As the catch is delivered terminal gets detached. Hence it is utilized to take contribution from users. This information can be high or low voltage that depend on that one terminal is associated with which source.

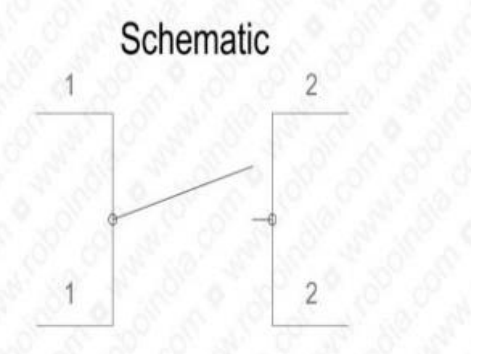

Fig 7: Schematic Diagram of Push Button

\section{Light dependent resistor (LDR)}

It is a basically photoconductivity device. A photoresistor also known as a light dependent resistor LDR, it is a passive component which decrease the resistance with respect to the receiving luminosity on the components sensitive surface. It works on the principle of voltage division. It has three terminals VCC(5volts), Ground and voltage divider point(V).
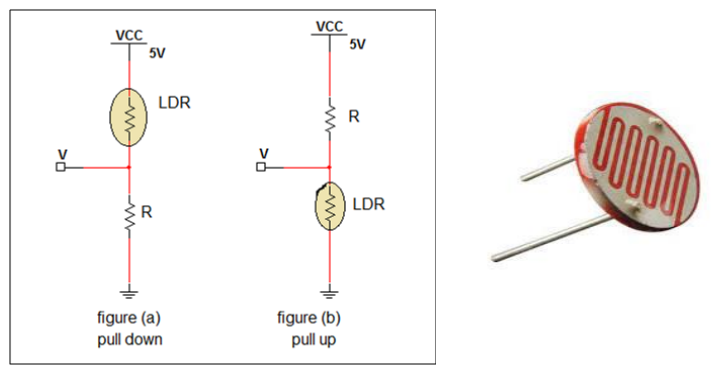

Fig 8: light dependent resistor (LDR)

\section{SOLAR PANEL}

A solar panel is a group of solar cells. A solar battery may be a set of solar cells electrical phenomenon modules electrically connected and mounted on structure. An electrical phenomenon module is prepackaged, connected assembly of solar cells. The solar battery will be used as a bigger electrical phenomenon system to come up with and provide electricity in business and residential applications.

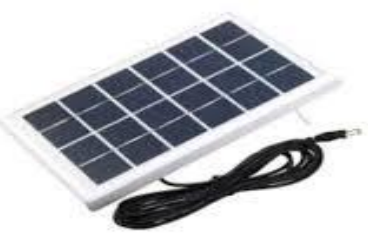

Fig 9: Solar panel

A solar cell is a specialized semiconductor device diode that converts visible light into direct current. Photovoltaic cells are an integral part of solar electric energy systems, which are becoming an increasingly important as alternative is sources of utility power.

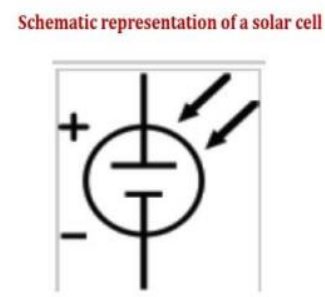

Fig 10: simple representation of solar cell

\section{FOUR WHEELS}

These wheels are rubber tire which has rough surface to move the upper wooden board with the help of motor rotation. Four wheels, in this two Wheels Run by D.C motor which are supported to rotate another two wheels.

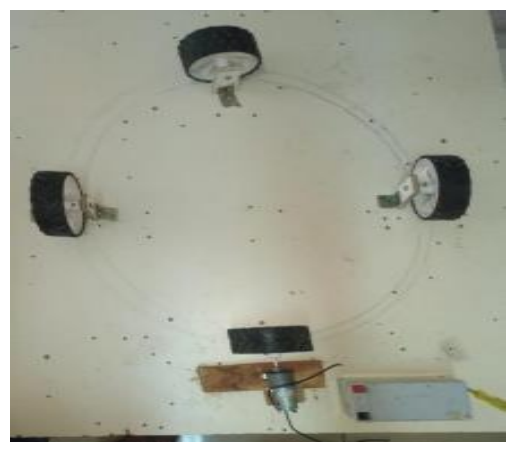

Fig. 11: Four wheels

\section{HARDWARE SETUP OPERATIONAND MEASURMENT OF POWER}

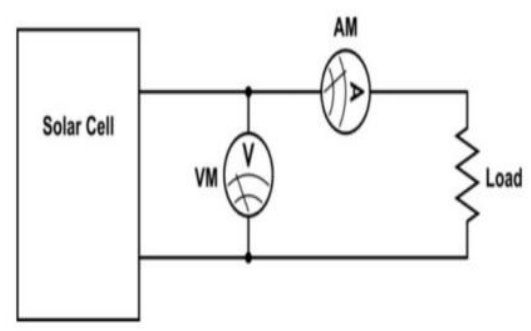

Fig 12: Solar panel connected to resistive load. 


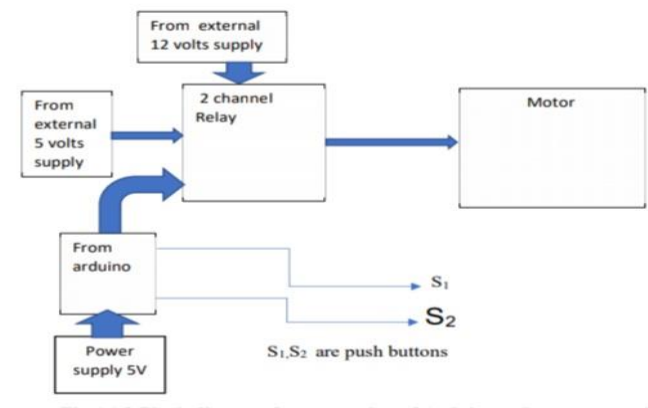

Fig 13: Block diagram for connection of Arduino, relay, motor and push buttons

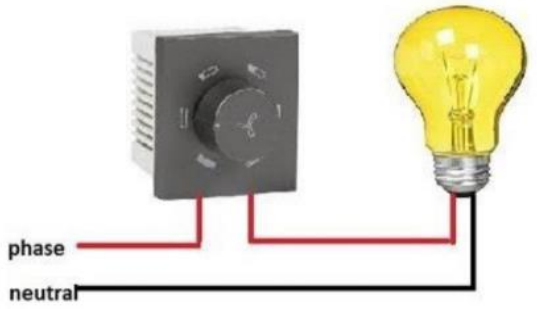

Fig 14: Incandescent bulb light intensity changed with the help of d.c speed regulator

Irradiance, a radiometric amount, measured in watts per square measure $\left(\mathrm{W} / \mathrm{m}^{2}\right)$

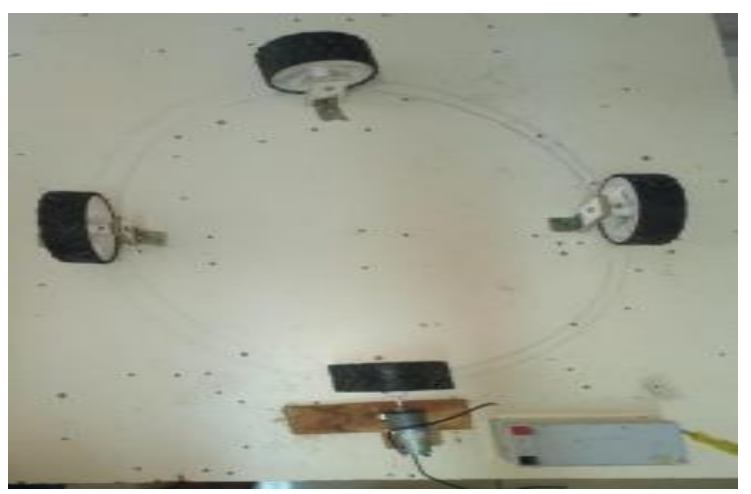

Fig 15: Four wheels D.C motor

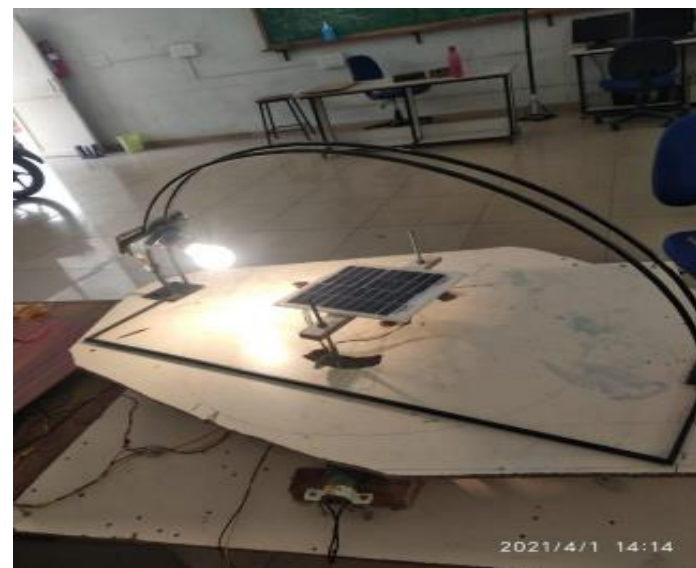

Fig 16: Solar panel and incandescent bulb setup

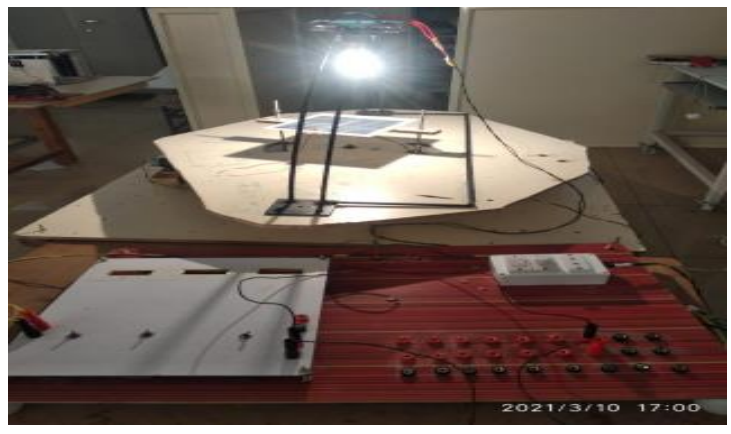

Fig 17: D.C regulator, load connection

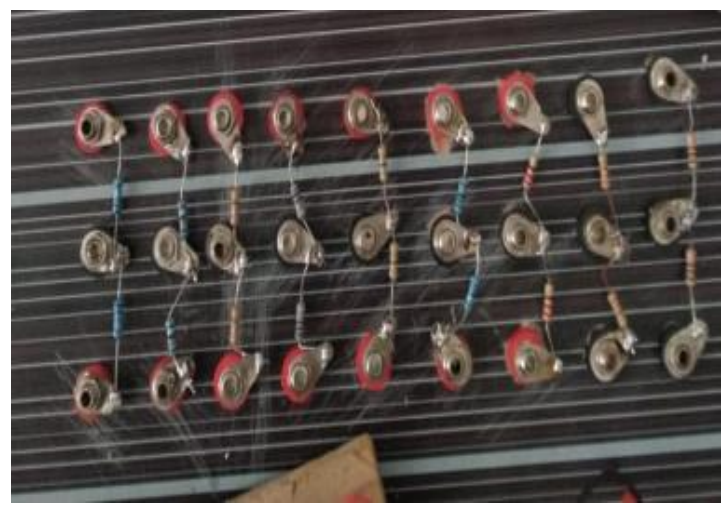

Fig 18: Resistive load as per requirement.

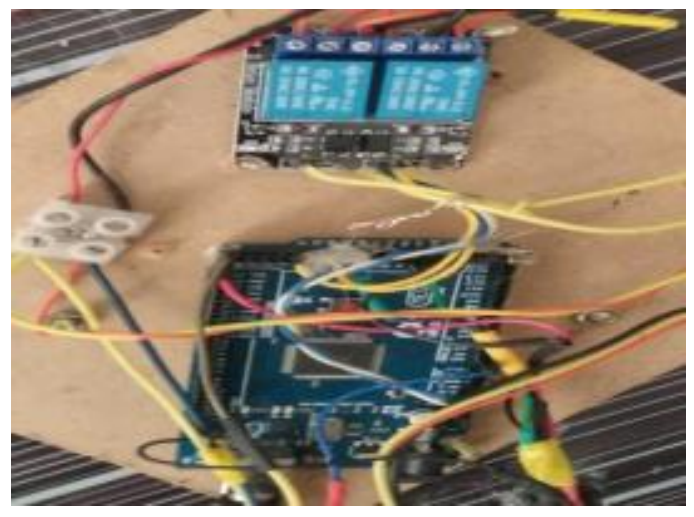

Fig 19: Two channel relay with Arduino snapshot

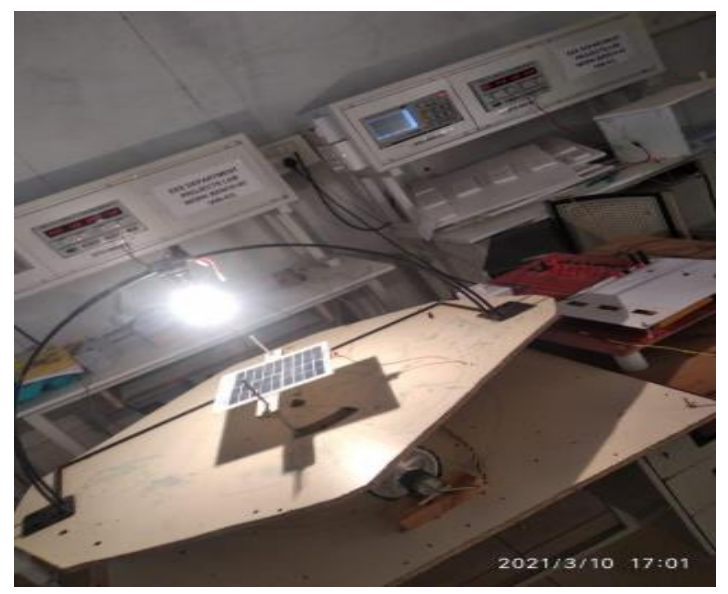

Fig 20: Hardware setup snapshot RPS,bulb at $90^{\circ}$. 


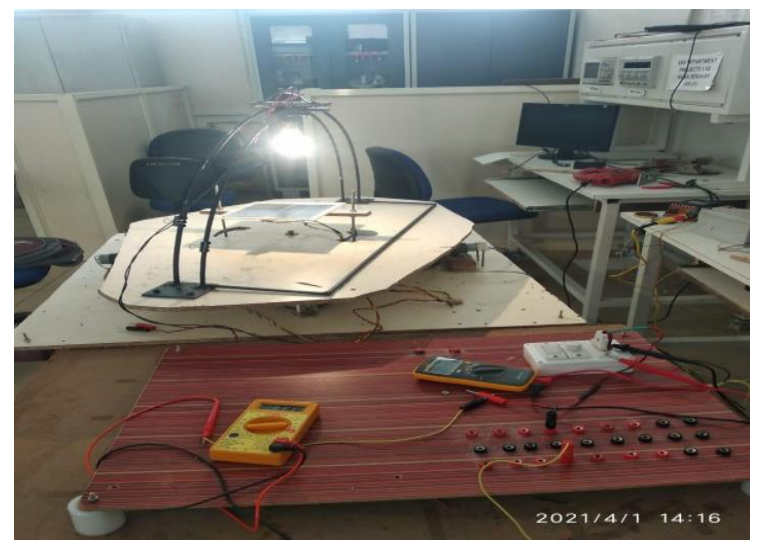

Fig 21: Snapshot of solar power measurement.

\section{PROCEDURE}

- Connect the power connector to Arduino from CPU for $5 \mathrm{~V}$.

- A 5V D.C supply given to relay input.

- A 12V D.C supply taken from D C regulated power supply for motor input.

- A 230V A.C supply given to Incandescent bulb through voltage regulator for varying light intensity.

- Connect required connection from Arduino,2 Channel Relay, Switches motors and main A.C supply.

- Dump the program into the Arduino.

- Switch ON all power supply.

- Set the solar panel at $0^{\circ}$.

- Place LDR at solar panel for light intensity measurement.

- Move the incandescent bulb at various degrees as $15^{\circ}$ to $90^{\circ}$.

- Connect the load across Solar output terminals.

- Measure the voltage and current by placing ammeter in series and voltmeter in parallel to the load and power is calculated from readings.

- Set solar panel at $23.5^{\circ},-23.5^{\circ}$ and move the

\begin{tabular}{|c|c|c|c|}
\hline $\mathrm{R}($ Ohms $)$ & $\mathrm{V}$ (Volts) & $\mathrm{I}(\mathrm{mA})$ & $\mathrm{P}(\mathrm{mW})$ \\
\hline 10 & 0.05 & 2.34 & 0.127 \\
\hline 20 & 0.071 & 2.34 & 0.166 \\
\hline 47 & 0.121 & 2.34 & 0.463 \\
\hline 75 & 0.198 & 2.34 & 0.463 \\
\hline 220 & 0.521 & 2.33 & 1.21 \\
\hline 330 & 0.765 & 2.32 & 1.77 \\
\hline 470 & 1.144 & 2.27 & 2.59 \\
\hline 660 & 1.492 & 2.28 & 3.4 \\
\hline
\end{tabular}

incandescent bulb (high intensity only) at $90^{\circ}$ and measure voltage, current and calculate the power.

\section{EXPERIMENTAL RESULTS}

\section{SOLAR PANEL AT $0^{\circ}$ DEGREE}

(a) incandescent bulb at $15^{\circ}$ high light intensity

Table 1: Incandescent Bulb At 15 Degrees High Light Intensity

\begin{tabular}{|c|c|c|c|}
\hline $\begin{array}{c}\text { Resistance } \\
\text { (ohms) }\end{array}$ & Voltage(volts) & Current(mA) & Power(mW) \\
\hline 10 & 0.04 & 1.95 & 0.078 \\
\hline
\end{tabular}

\begin{tabular}{|c|c|c|c|}
\hline 20 & 0.059 & 1.95 & 0.115 \\
\hline 47 & 0.101 & 1.94 & 0.195 \\
\hline 75 & 0.165 & 1.94 & 0.32 \\
\hline 220 & 0.43 & 1.92 & 0.82 \\
\hline 330 & 0.629 & 1.91 & 1.20 \\
\hline 470 & 0.951 & 1.89 & 1.79 \\
\hline 660 & 1.21 & 1.88 & 2.28 \\
\hline
\end{tabular}

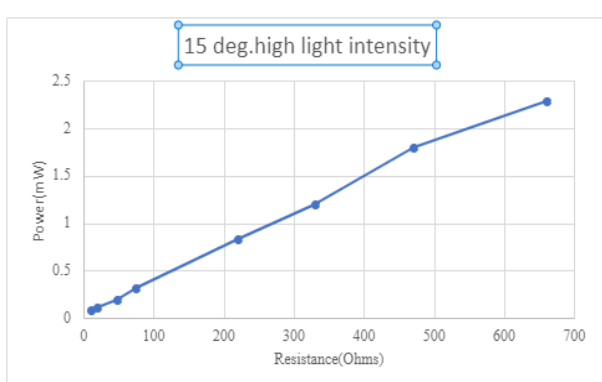

Fig 22(a): $R$ versus $P$ incandescent bulb at $15^{\circ}$ high light intensity.

\section{(b) incandescent bulb at $15^{\circ}$ less light intensity}

Table 2: incandescent bulb at 15 degrees less light intensity

\begin{tabular}{|c|c|c|c|}
\hline Resistance(Ohms) & Voltage(Volts) & Current(mA) & Power(mW) \\
\hline 10 & 0.033 & 1.67 & 0.052 \\
\hline 20 & 0.049 & 1.64 & 0.08 \\
\hline 47 & 0.084 & 1.63 & 0.13 \\
\hline 75 & 0.13 & 1.63 & 0.22 \\
\hline 220 & 0.35 & 1.62 & 0.58 \\
\hline 330 & 0.53 & 1.61 & 0.85 \\
\hline 470 & 0.80 & 1.6 & 1.28 \\
\hline 660 & 1.05 & 1.61 & 1.67 \\
\hline
\end{tabular}

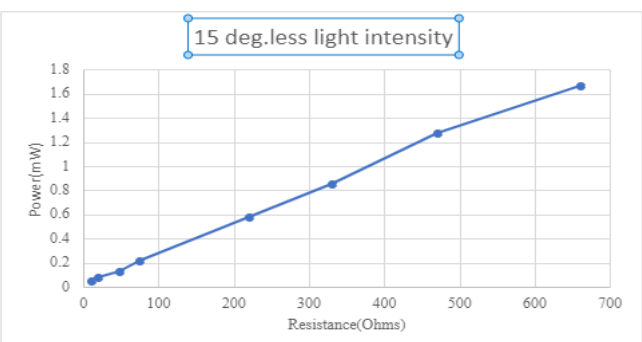

Fig. 22(b) $R$ versus $P$ incandescent bulb at $15^{\circ}$ less light intensity

(c) incandescent bulb at 30 degrees less light intensity

Table 3: incandescent bulb at $\mathbf{3 0}$ degrees less light intensity

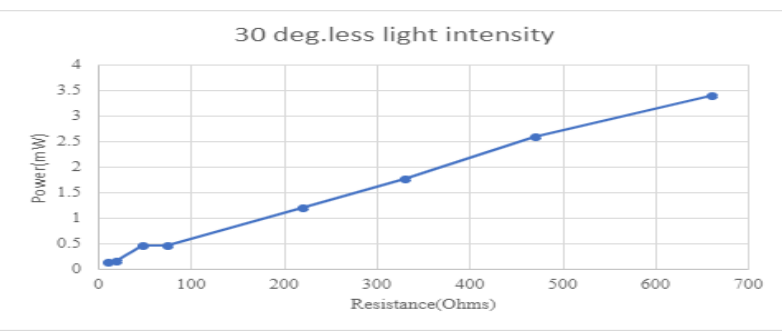

Fig.22 (c) $R$ versus $P$ incandescent bulb at $30^{\circ}$ less light intensity 
(d) incandescent bulb at 30 degrees high light intensity

Table 4: incandescent bulb at 30 degrees high light intensity

\begin{tabular}{|c|c|c|c|}
\hline Resistance(ohms) & Voltage(volts) & Current(mA) & Power(mW) \\
\hline 10 & 0.111 & 4.42 & 0.49 \\
\hline 20 & 0.135 & 4.41 & 0.595 \\
\hline 47 & 0.23 & 4.4 & 1.012 \\
\hline 75 & 0.370 & 4.39 & 1.624 \\
\hline 220 & 0.967 & 4.34 & 4.19 \\
\hline 330 & 1.42 & 4.31 & 6.12 \\
\hline 470 & 2.2 & 4.25 & 9.46 \\
\hline 660 & 2.73 & 4.20 & 11.47 \\
\hline
\end{tabular}

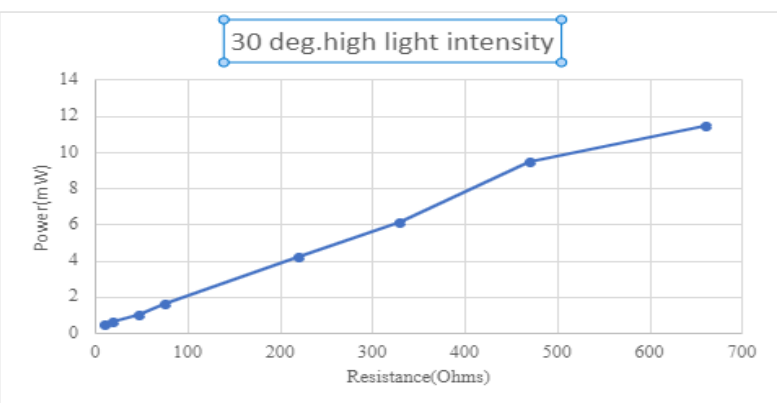

Fig 22 (d) $R$ verses $P$ incandescent bulb at $30^{\circ}$ high light intensity

(e) incandescent bulb at $45^{\circ}$ less light intensity

\begin{tabular}{|c|c|c|c|}
\hline Resistance(ohms) & Voltage(volts) & Current(mA) & Power(mA) \\
\hline 10 & 0.097 & 4.2 & 0.407 \\
\hline 20 & 0.127 & 4.18 & 0.53 \\
\hline 47 & 0.216 & 4.15 & 0.896 \\
\hline 75 & 0.339 & 4.02 & 1.362 \\
\hline 220 & 0.905 & 3.98 & 3.6 \\
\hline 330 & 1.28 & 3.87 & 4.96 \\
\hline 470 & 1.878 & 3.73 & 7.0 \\
\hline 660 & 2.4 & 3.74 & 9.0 \\
\hline
\end{tabular}

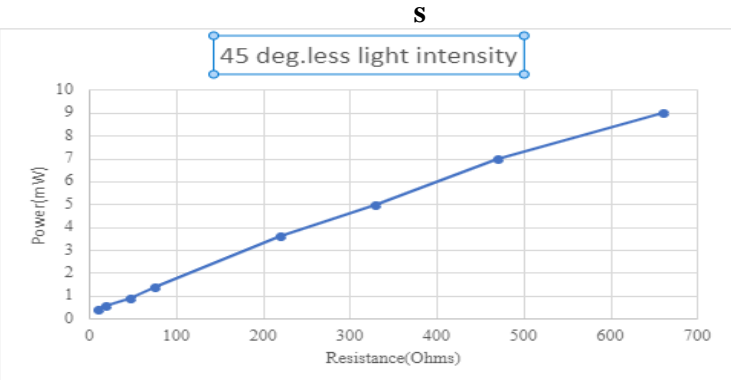

Fig 22(e) $R$ versus $P$ incandescent bulb at $45^{\circ}$ less light intensity

(f) incandescent bulb at $45^{\circ}$ high light intensity

Table 6: incandescent bulb at $45^{\circ}$ high light intensity

\begin{tabular}{|c|c|c|c|}
\hline Resistance(ohms) & Voltage(volts) & Current(mA) & Power(mW) \\
\hline 10 & 0.37 & 10.23 & 3.06 \\
\hline 20 & 0.308 & 10.19 & 3.13 \\
\hline
\end{tabular}

\begin{tabular}{|c|c|c|c|}
\hline 47 & 0.521 & 9.14 & 4.76 \\
\hline 75 & 0.84 & 9.15 & 7.68 \\
\hline 220 & 2.19 & 9.85 & 21.57 \\
\hline 330 & 3.21 & 9.75 & 31.29 \\
\hline 470 & 4.8 & 9.58 & 45.9 \\
\hline 660 & 5.96 & 9.19 & 50.17 \\
\hline
\end{tabular}

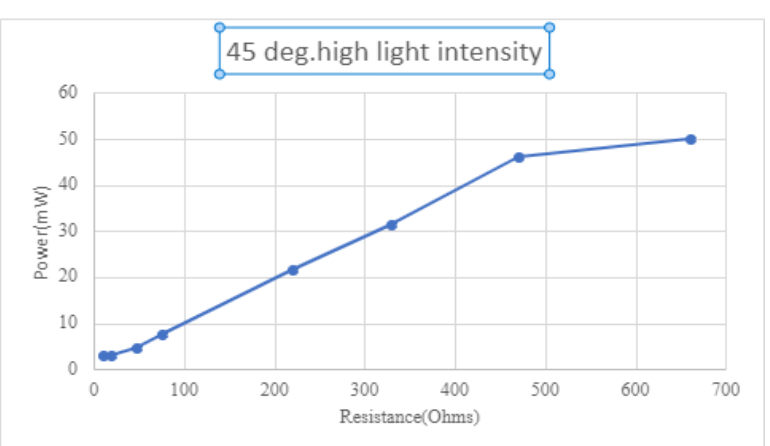

Fig.22 (f) $R$ versus $P$ incandescent bulb at $45^{\circ}$ high light intensity

(g) Incandescent bulb at 60 degrees less light intensity

Table 7: Incandescent bulb at 60 degrees less light intensity

\begin{tabular}{|c|c|c|c|}
\hline Resistance(Ohms) & Voltage(Volts) & Current(mA) & Power(mW) \\
\hline 10 & 0.13 & 6.25 & 0.81 \\
\hline 20 & 0.191 & 6.31 & 1.205 \\
\hline 47 & 0.328 & 6.21 & 2.04 \\
\hline 75 & 0.516 & 6.09 & 3.14 \\
\hline 220 & 1.329 & 5.91 & 7.8 \\
\hline 330 & 1.89 & 5.74 & 10.84 \\
\hline 470 & 2.94 & 5.64 & 16.58 \\
\hline 660 & 3.58 & 5.52 & 19.76 \\
\hline
\end{tabular}

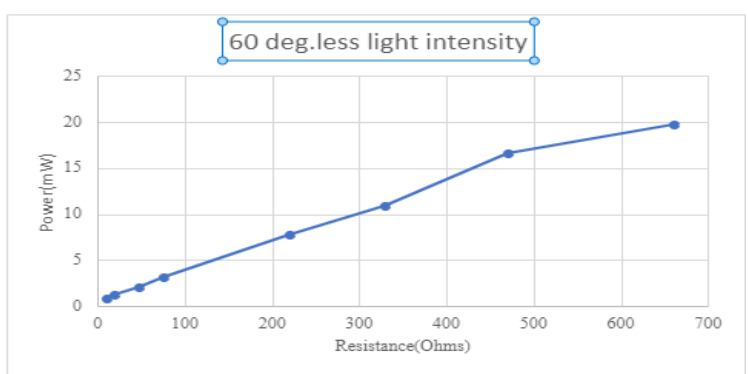

Fig 22 (g) $R$ versus $P$ incandescent bulb at $60^{\circ}$ less light intensity

(h) Incandescent bulb at $60^{\circ}$ degrees high light intensity

Table 8: incandescent bulb at $60^{\circ}$ high light intensity

\begin{tabular}{|c|c|c|c|}
\hline Resistance(Ohms) & Voltage(Volts) & Current(mA) & Power(mW) \\
\hline 10 & 0.414 & 17.84 & 17.385 \\
\hline 20 & 0.54 & 17.6 & 9.504 \\
\hline 47 & 0.356 & 17.45 & 23.66 \\
\hline 75 & 1.5 & 17.28 & 25.937 \\
\hline
\end{tabular}




\begin{tabular}{|c|c|c|c|}
\hline 220 & 3.74 & 16.73 & 62.57 \\
\hline 330 & 5.37 & 16.33 & 87.69 \\
\hline 470 & 7.84 & 15.52 & 121.67 \\
\hline 660 & 8.27 & 12.78 & 105.69 \\
\hline
\end{tabular}

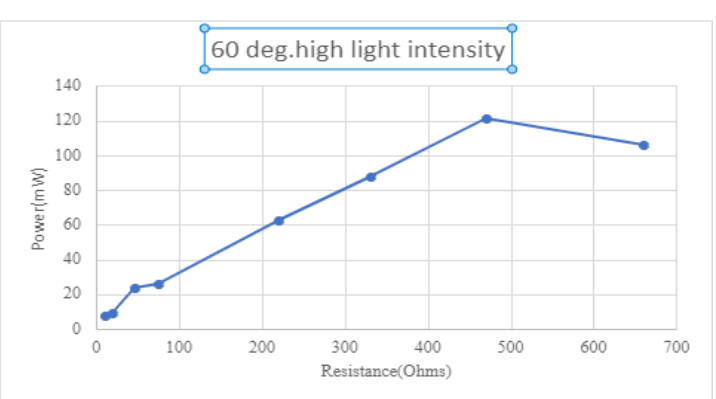

Fig 22 (h) $R$ versus $P$ incandescent bulb at $60^{\circ}$ high light intensity

(i) incandescent bulb at 75 degrees less light intensity

Table 9: Incandescent bulb at 75 degrees less light intensity

\begin{tabular}{|c|c|c|c|}
\hline Resistance(Ohms) & Voltage(Volts) & Current(mA) & Power(mW) \\
\hline 10 & 0.18 & 8.76 & 1.57 \\
\hline 20 & 0.268 & 8.75 & 2.34 \\
\hline 47 & 0.512 & 8.65 & 4.42 \\
\hline 75 & 0.742 & 8.58 & 6.36 \\
\hline 220 & 1.874 & 8.32 & 15.59 \\
\hline 330 & 2.634 & 8.05 & 21.2 \\
\hline 470 & 4.08 & 7.64 & 31.17 \\
\hline 660 & 5.06 & 7.54 & 38.15 \\
\hline
\end{tabular}

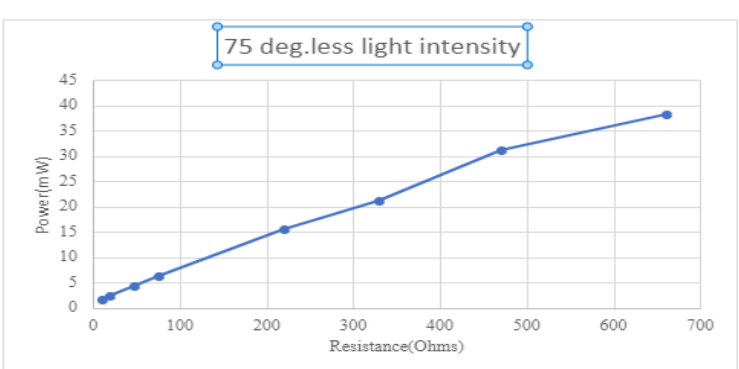

Fig 22 (i) $R$ versus $P$ incandescent bulb at $75^{\circ}$ less light intensity

(j) Incandescent bulb at 75 degrees high light intensity

Table 10: Incandescent bulb at 75 degrees high light intensity

\begin{tabular}{|c|c|c|c|}
\hline Resistance(Ohms) & Voltage(Volts) & Current(mA) & Power(mW) \\
\hline 10 & 0.334 & 27.1 & 9.05 \\
\hline 20 & 0.59 & 26.9 & 15.87 \\
\hline 47 & 1.19 & 26.2 & 31.23 \\
\hline 75 & 1.95 & 25.2 & 49.14 \\
\hline 220 & 5.19 & 24.3 & 126.11 \\
\hline 330 & 7.53 & 23.6 & 177.7 \\
\hline 470 & 8.44 & 16.6 & 140 \\
\hline 660 & 8.65 & 13.37 & 115.65 \\
\hline
\end{tabular}

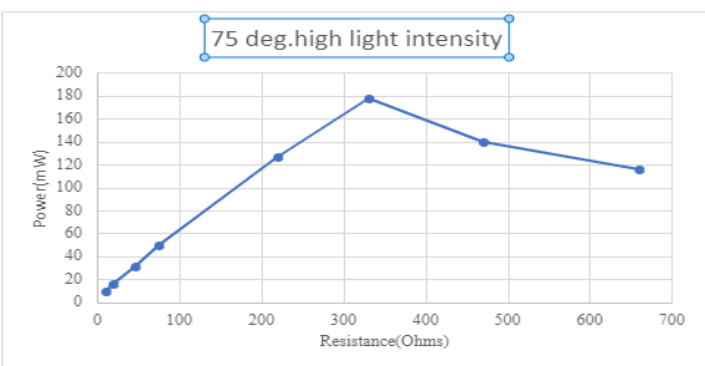

Fig 22 (j) $R$ versus $P$ incandescent bulb at $75^{\circ}$ high light intensity

(k) Incandescent bulb at $90^{\circ}$ less light intensity

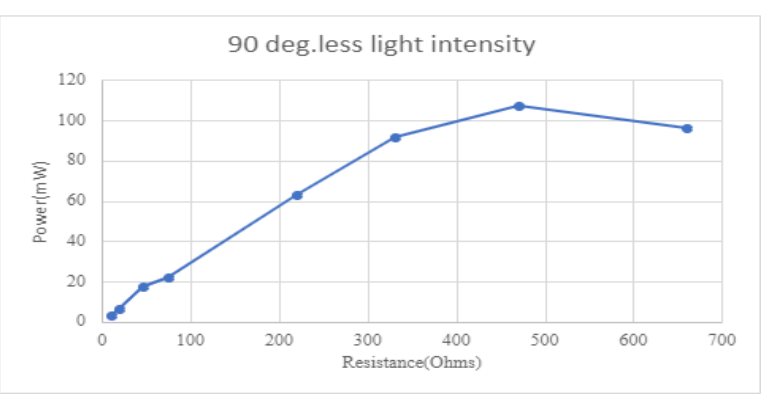

Fig.4.4.1 ( $k$ ) R versus $P$ incandescent bulb at $90^{\circ}$ less light intensity

\section{(l) Incandescent bulb at $90^{\circ}$ high light intensity}

Table 11: Incandescent bulb at $90^{\circ}$ less light intensity

\begin{tabular}{|c|c|c|c|}
\hline Resistance(Ohms) & Voltage(Volts) & Current(mA) & Power(mW) \\
\hline 10 & 0.66 & 30.2 & 19.9 \\
\hline 20 & 0.674 & 29.9 & 19.3 \\
\hline 47 & 1.414 & 29.4 & 41.5 \\
\hline 75 & 2.18 & 28.8 & 62.9 \\
\hline 220 & 6.05 & 28.3 & 171.21 \\
\hline 330 & 7.83 & 24.5 & 191.83 \\
\hline 470 & 8.41 & 17.1 & 143.6 \\
\hline 660 & 8.61 & 13.5 & 116.23 \\
\hline
\end{tabular}

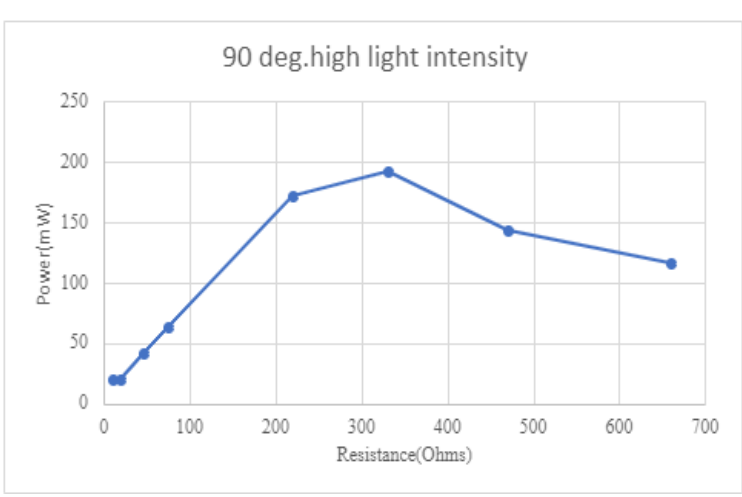

Fig. 22 (I) $R$ versus $P$ incandescent bulb at $90^{\circ}$ high light intensity 
Solar panel at $-23.5^{\circ}$ and bulb at $90^{\circ}$ high light intensity

\begin{tabular}{|c|c|c|c|}
\hline Resistance(Ohms) & Voltage(Volts) & Current(mA) & Power(mW) \\
\hline 10 & 0.243 & 19.6 & 4.76 \\
\hline 20 & 0.426 & 19.5 & 8.307 \\
\hline 47 & 0.974 & 19.3 & 18.79 \\
\hline 75 & 1.62 & 19.1 & 30.94 \\
\hline 220 & 4.02 & 18.8 & 75.57 \\
\hline 330 & 5.93 & 18.2 & 107.9 \\
\hline 470 & 7.59 & 15.13 & 114.83 \\
\hline 660 & 7.99 & 12.32 & 98.43 \\
\hline
\end{tabular}

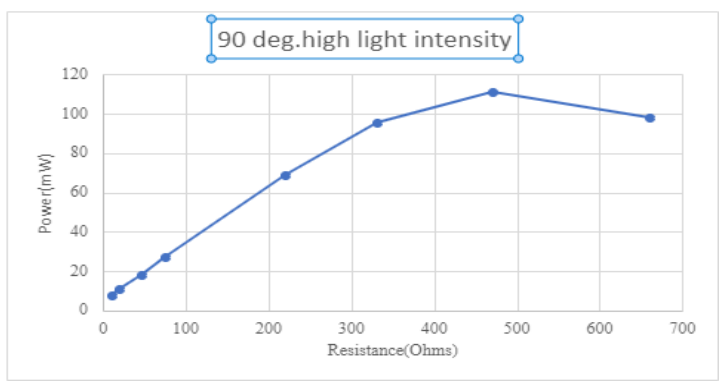

Fig 23: Solar panel at $-23.5^{\circ} R$ versus $P$ incandescent bulb at $\mathbf{9 0}^{\circ}$ high light intensity

Solar panel at $+23.5^{\circ}$ and bulb at $90^{\circ}$ high light intensity.

\begin{tabular}{|l|l|l|l|}
\hline $\begin{array}{l}\text { Resistance } \\
(\text { Ohms })\end{array}$ & $\begin{array}{l}\text { Voltage } \\
(\text { Volts })\end{array}$ & Current(mA) & Power(mW) \\
\hline 10 & 0.417 & 18.55 & 7.735 \\
\hline 20 & 0.572 & 18.4 & 10.524 \\
\hline 47 & 0.978 & 18.11 & 17.711 \\
\hline 75 & 1.54 & 17.74 & 27.319 \\
\hline 220 & 3.928 & 17.45 & 68.54 \\
\hline 330 & 5.62 & 17.05 & 95.82 \\
\hline 470 & 7.5 & 14.84 & 111.3 \\
\hline 660 & 7.99 & 12.27 & 98.03 \\
\hline
\end{tabular}

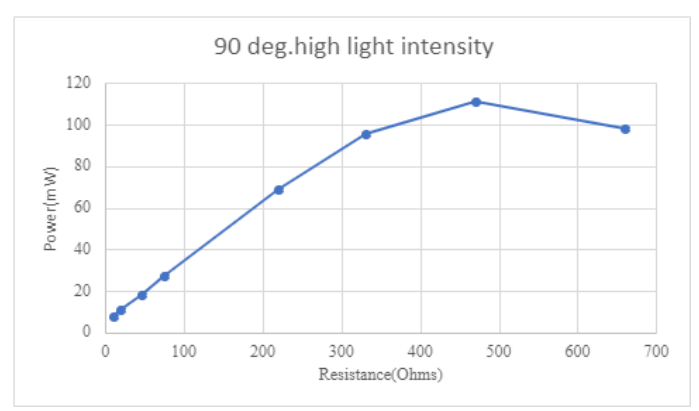

Fig 24: Solar panel at $23.5^{\circ} R$ versus $P$ incandescent bulb at $\mathbf{9 0}^{\circ}$ high light intensity.

Hence from all the results it is observe that the maximum power output comes from Solar panel at $0^{\circ}$ and incandescent bulb light (high light intensity) at $90^{\circ}$.In this case the graph shows maximum power output the at $330 \mathrm{ohms}$ resistance.

\section{CONCLUSION}

- The solar panel parameters like voltage, current have been measured.

- At high light intensity solar panel produce more power compared to less light intensity.
- The solar panel output characteristics drawn between output power and load resistance.

\section{Future scope:}

By changing the brightness of the light with degree of rotation/day of the year and time of the day. This paper can be extended as follows

- Single axis

- Dual axis

\section{- No tracking}

It is suggested, for future work, that the Framework be made with higher exactness sensors and furthermore be made to have the capacity to store information obtained from the estimations to guarantee legitimate observing and Assessment. Additionally, the framework can be made to Utilize a DC supply from a battery and a Charging circuit can be added so as the Battery can be charged, this would make the Framework more versatile.

\section{REFERECES}

1. Design and implementation of solar energy measurement and monitoring system Agbetuyi Ayoade Felix, Orovwode Hope, Olowoleni Joseph, Nwangwu Chukwuebuka Authors are from the department of Electrical and Information Engineering, Covenant University, Cannanland, Ota, Ogun State, Nigeria. Corresponding Email address: ayo.agbetuyi@covenantuniversity.edu.ng 2018 IEEE PES/IAS PowerAfrica (Postgradute Forum).

2. Estimation of Solar Irradiance on Solar Fields: an Analytical Approach and Experimental Results Samer Yassin Alsadi, Member, IEEE and Yasser Fathi Nassar.

3. Effects of the Solar Module Installing Angles on the Output Power Chang Ying-Pin 1 Shen Chung-Huang 2 (Dept. of Electrical Engineering, Nan Kai Institute of Technology, 568 Chungcheng Rd., Tsaotun, Nantou, Taiwan 542).

4. EVALUATION OF TRACKING FLAT PLATE AND CONCENTRATOR PV SYSTEMS Tom Lepley Phasor Energy Company, Phoenix, AZ Bob Hammond and Alex Harris Arizona State University, Tempe, Arizona.

5. Energy Conversion Efficiency of a Novel Hybrid Solar System for Photovoltaic, Thermoelectric, and Heat Utilization Dajiang Yang and Huiming Yin.

6. Electric traction and Renewable energy sources book by M. Rajalingam. 